\title{
Effects of Elliptical Hole on the Correlation of Natural Frequency with Buckling Load of Basalt Laminates Composite Plates
}

https://doi.org/10.1515/secm-2020-0021

Received Mar 17, 2020; accepted Jun 01, 2020

\begin{abstract}
Recently, basalt fiber reinforced polymer (BFRP) is acknowledged as an outstanding material for the strengthening of existing concrete structure, especially it was being used in marine vehicles, aerospace, automotive and nuclear engineering. Most of the structures were subjected to severe dynamic loading during their service life that may induce vibration of the structures. However, free vibration studied on the basalt laminates composite plates with elliptical cut-out and correlation of natural frequency with buckling load has been very limited. Therefore, effects of the elliptical hole on the natural frequency of basalt/epoxy composite plates was performed in this study. Effects of stacking sequence $(\theta)$, elliptical hole inclination $(\phi)$, hole geometric ratio $(\mathrm{a} / \mathrm{b})$ and position of the elliptical hole were considered. The numerical modeling of free vibration analysis was based on the mechanical properties of BFRP obtained from the experiment. The natural frequencies as well as mode shapes of basalt laminates composite plates were numerically determined using the commercial program software (ABAQUS). Then, the determination of correlation of natural frequencies with buckling load was carried out. Results showed that elliptical hole inclination and fiber orientation angle induced the inverse proportion between natural frequency and buckling load.
\end{abstract}

Keywords: Basalt fiber reinforced polymer, Elliptical hole, Finite element analysis, Free vibration

\footnotetext{
*Corresponding Author: WooYoung Jung: Department of Civil Engineering, Gangneung-Wonju National University, Gangneung-si, Gangwon-do [25457], South Korea; Email: woojung@gwnu.ac.kr Buntheng Chhorn: Department of Civil Engineering, GangneungWonju National University, Gangneung-si, Gangwon-do [25457], South Korea; Email: buntheng.chhorn@yahoo.com
}

\section{Introduction}

Fiber reinforced polymers are very significant in engineering applications owing to their excellent characteristic such as high strength-to-weight ratios, high stiffness, controllability of property, low coefficient of thermal expansion, admirable corrosion resistance and worthy fatigue resistance [1-4]. Therefore, they have been commonly used in numerous civil engineering fields such as: the aerospace industry, marine vehicles, chemical, automotive, nuclear engineering and space vehicle. In design structure under the dynamics loading, reduction of resonant frequency is significant to improve the performance of constructed structures. Working optimum frequency and prediction of natural frequency in structure is thus required.

Cutouts have been commonly used in practical applications such as: altering the natural frequency, damage inspection, and access ports for electrical and mechanical systems. Damping and natural frequency properties of composite structures were investigated by many researchers [5-9]. Free vibration of symmetrically laminate composite beam was studied by Chandrashekhara et al. [5]. In calculation, first order shear deformation and rotary inertia effects were carried out for analysis. Turvey et al. [6] studied on effects of anisotropy, boundary conditions and hole size ratio on the natural frequency of square glass fiber reinforced polymer. Clamped, free edge support and simply support were performed as boundary conditions. Results showed that finite element and experiment were agreement with each other. Free vibration of rectangular plates with rectangular cutouts at the center was considered by Liew et al. [7]. Combination of clamped and simply support condition were implemented. Aydogdu [8] was interested in vibration analysis of laminate composite beam with various boundary conditions. Ritz method with a 3 degree of freedom shear deformable beam theory was used to analyze free vibration frequencies. Erkliğ et al. [9] studied the effects of hole cutouts (square, circular, triangular and elliptical) on the natural frequency of laminate composite plates. Moreover, effects of fiber orientation, cutout

əopen Access. (c) 2020 B. Chhorn and W. Jung, published by De Gruyter. (cc) BY bution 4.0 License 
position and length of the plate were considered. Results showed that cutout location and fiber orientation angle are the most crucial parameters of the natural frequency.

An analytical method based on Rayleigh-Ritz and Fourier-Bessel series expansion method was developed by Jhung et al. [10] to investigate the effects of an eccentric hole on natural frequency of the circular plate. The third-order shear deformation theory was employed to analyze free vibration and buckling finite strip analysis of composite plates by Ovesy and Fazilati [11]. The effect of cutout based on two different modeling methods (spline and semi-analytical approaches) was consider. Sivakumar et al. [12] used first order shear deformation theory to investigate the free vibration response of composite plates with elliptical hole cutout. [13, 14] implemented a finite element formulation based on Hamilton's principle and higher order shear deformation theory (HSDT) to study the free vibration responses of thick square composite plates. The plates with central rectangular cut-out were considered. The dynamic stability of curved panels having cutout in the framework of first order shear deformation theory (FSDT) based on the Bolotin's approach was investigated by Sahu and Datta [15]. Reddy and Palaninathan [16] considered the free vibration response of composite plate. A general high-precision triangular plate bending finite element and a nine-node isoperimetric plate with FSDT were carried out.

The free vibration response of cylindrical skew panels and skew plates using finite element method as well as experiment were studied [17-22]. The effects of aspect ratio and skew angle on the natural frequencies of isotropic skew plates were considered. Moreover, the effects of aspect ratio, skew angle and fiber orientation angle of the natural frequencies of laminate composite plates have been studied. Although, a numerous of the literature have been studied on either numerical or experimental approach for the free vibration analysis of laminate composite plates with various cut-out, there were very limited publication on the effect of elliptical hole on the correlation of natural frequency with buckling load of basalt laminates composite plates.

In this study, the evaluation of the effects of elliptical cut-out on the natural frequency of BFRP laminate composite plates was carried out. The natural frequencies as well as mode shapes of basalt laminates composite plates are numerically obtained using the commercial program software (ABAQUS). Effects of fiber orientation angle, elliptical hole inclination, elliptical hole aspect ratio and thickness of laminate composite plates were considered. The numerical modeling of free vibration analysis based on the mechanical properties of BFRP was received from the ex- periment. Then, the correlation of natural frequency with buckling load was implemented.

\section{Experimental study on mechanical properties of BFRP}

\subsection{Materials}

In this study, basalt plain woven fabrics was provided by Basalt Fiber Tech company where situated in Australia. The filament diameters of basalt plain woven fabrics are about $13-20 \mu \mathrm{m}$. Epoxy resin was supplied by Kukdo Chemical company in South Korea. Its viscosity (cps at $25^{\circ} \mathrm{C}$ ) range between 11500-13500 and its mixing ratio (resin: hardener) is of 100:33. The material properties of basalt fiber as well as epoxy resin were listed in Table 1. To obtain the mechanical properties of epoxy resin, ASTM D2344/D2344M-03 [23] standard was conducted.

Table 1: Material properties of basalt fiber fabric and epoxy

\begin{tabular}{lcc}
\hline Items & $\begin{array}{c}\text { Basalt fiber } \\
\text { fabric }\end{array}$ & Epoxy \\
\hline Thickness $(\mathrm{mm})$ & 0.125 & - \\
Density $\left(\mathrm{g} / \mathrm{cm}^{2}\right)$ & 2.8 & - \\
Tensile strength $(\mathrm{MPa})$ & 4840 & 250 \\
Elastic modulus & 89 & - \\
Elongation rate $(\%)$ & 3.15 & - \\
Heat distortion temperature $\left({ }^{\circ} \mathrm{C}\right)$ & - & 61 \\
\hline
\end{tabular}

\subsection{Testing program}

In this work, five plies of BFRP were made of basalt plain woven fabrics and epoxy resin by means of a vacuum infusion process as shown in Figure 1(a). after completing the vacuum process 24 hours, the BFRP plate was kept in the temperature controlled room for two hours at the temperature of $80^{\circ} \mathrm{C}$. Then the manufactured BFRP plate was cut to the required dimension for tensile and shear coupon test specimens by a water jet cutter. The dimension of tensile and shear test was conducted accordingly to ASTM D 3039/D 3039M-00 [24] and D 4255/D 4255M - 01 [25], respectively. Two aluminum plates of $25 \mathrm{~mm}$ length, $15 \mathrm{~mm}$ width and $1.5 \mathrm{~mm}$ thickness were attached on each side of the tensile specimens to ensure uniform load transfer and avoid stress concentration. To obtain the stain of spec- 

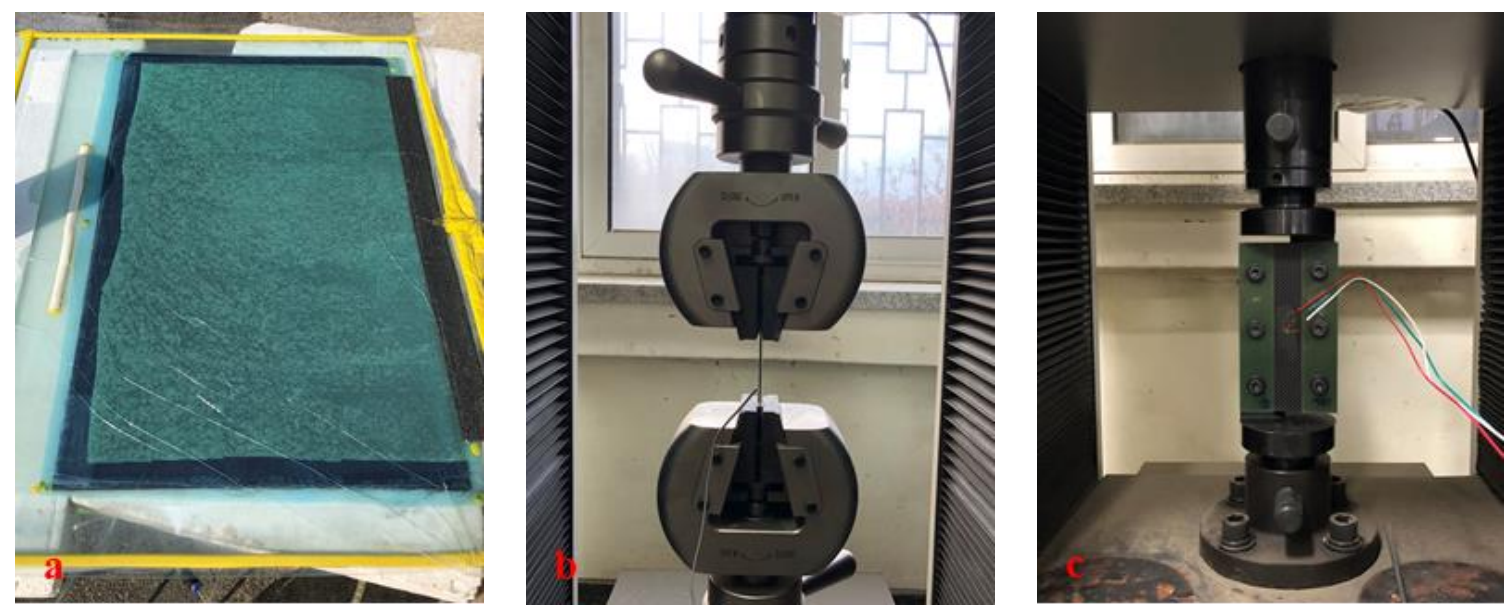

Figure 1: (a) vacuum infusion process, (b) tensile testing and (c) shear testing

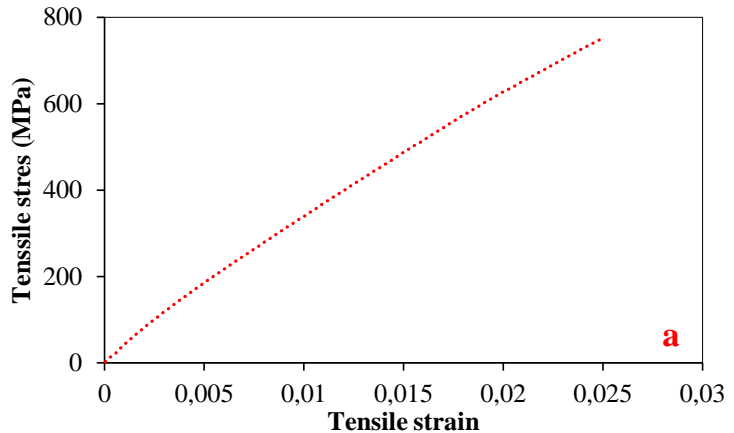

Figure 2: Stress-strain curve of: (a) tensile and (b) shear

imens, strain gauges were glued at the center of the specimens for tensile and shear testing as shown in Figure 1(b) and 1 (c), correspondingly.

To conduct the experiment of coupon test, Universal testing machine (model AST-MHA) in Gangneung-Wonju National University with capacity of $100 \mathrm{kN}$ was used as shown in Figure 1(b) and 1(c). Monotonic testing was performed with the strain rate of $0.01 / \mathrm{mm}$. The five specimens were conducted with the same condition of strain rate. Finally, the average results of tensile as well as shear testing were obtained from the each of five specimens.

\subsection{Experimental results}

The average stress-strain curve results of tensile and shear testing were plotted as illustrated in Figure 2(a) and 2(b), respectively. It was observed that the stress of the tensile specimen was increased linearly with proportional to increasing the tensile strain. This can be noted elastic region, where the deformation of the specimen returned to the original region when removing loading. Based on this ten-

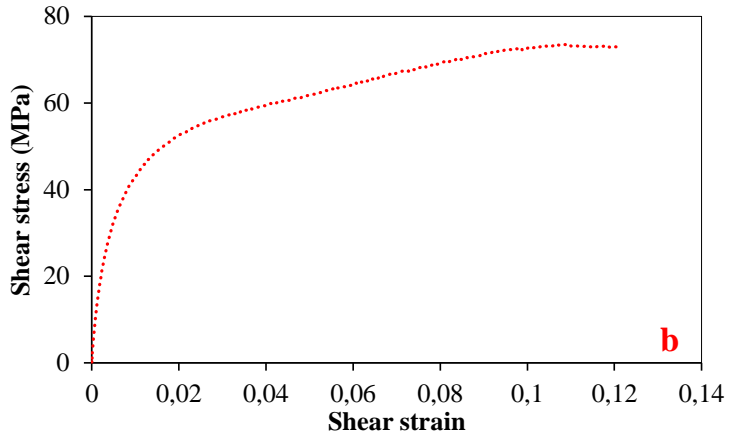

sile curve, it can be concluded that basalt fiber reinforced polymer (BFRP) is the elastic material. Elasticity module can be defined from the slop of proportional limit as described in (ASTM D 3039/D 3039M-00 [24]). Figure 2(b) was demonstrated that the stress-strain curve of the shear specimen was increasing non-linearly. It can be observed that this almost followed the bilinear curve. Firstly, it was increased rapidly and then changed to increas dramatically until failing. To obtain the shear module, it was determined in accordance with ASTM D2435/D2435M-01 [25]. To end, the elastic and shear module can be found and listed in Table 2. The mechanical properties of BFRP were used as

Table 2: Mechanical properties of BFRP

\begin{tabular}{lc}
\hline Properties & BFRP \\
\hline Density $\left(\mathrm{kg} / \mathrm{m}^{3}\right)$ & 2600 \\
Longitudinal modulus $E_{11}(\mathrm{GPa})$ & 37.03 \\
Transverse modulus $E_{22}(\mathrm{GPa})$ & 37.03 \\
Poisson's ratio $v_{12}$ & 0.290 \\
Shear modulus $G_{12}(\mathrm{GPa})$ & 2.370 \\
\hline
\end{tabular}


input in numerical modeling to determine the natural frequencies as well as the correlation of natural frequencies with buckling load of laminate composite plates.

\section{Finite element modeling}

\subsection{Numerical modeling}

The commercial finite element program ABAQUS was used to simulate the numerical investigation of the natural frequency of laminate composite plate as illustrated in Figure 3a. Appropriate elements were designated from the ABAQUS software library to suitably simulate the characteristic of the component of the free vibration analysis of laminate composite plate. A quadrilateral type eight-node shell elements (S8R) was sued to present the BFRP laminate composite that shell element is appropriate for modeling thin to adequately thick shell structure with membrane option. The shell element has six degrees of freedom at each node: 3 translations and other 3 rotations. 19874 quadrilateral S8R elements were used with a mesh size refine in the area of the elliptical hole as shown in Figure 3a. The analysis was carried out in plane stress. The plate was established of eight plies, each ply having a thickness of $0.125 \mathrm{~mm}$.

In this study, a thin rectangular plate of length (L) and width $(\mathrm{H})$ with an elliptical hole was considered. The ratio between the length $\mathrm{L}=200 \mathrm{~mm}$ and the width $\mathrm{W}=100 \mathrm{~mm}$ of the plate is $\mathrm{L} / \mathrm{W}=2$ and thickness $\mathrm{t}=1 \mathrm{~mm}$. The material properties of BFRP were listed in Table 2 and laid up in 8 plies. In application of laminate composite plates, various forms of the cut-out can be implemented for design purpose. The form of the cut-out was supposed to be an elliptical cut-out in the center of the plate. Thus, the effect of different elliptical hole inclination on the natural frequency was highlighted. The elliptical hole inclination was conducted with angle of $0^{\circ} 15^{\circ}, 30^{\circ}, 45^{\circ}, 60^{\circ}, 75^{\circ}$ and $90^{\circ}$. When the angle of the elliptical hole $\left(\phi=0^{\circ}\right)$, it means that major axis is parallel to the $\mathrm{xx}$ axis and when the angle $\left(\phi=90^{\circ}\right)$, the major axis is parallel to the yy axis. The major and minor diameter of elliptical hole was represented by 'b' and 'a', respectively as demonstrated in Figure $3 \mathrm{~b}$. Furthermore, the effect of different elliptical hole aspect ratios $(a / b)$ were considered. The major axis of the elliptical hole (b) is equal to $20 \mathrm{~mm}$ and the minor axis (a) is varied 4, 8, 12, 16, and $20 \mathrm{~mm}$.

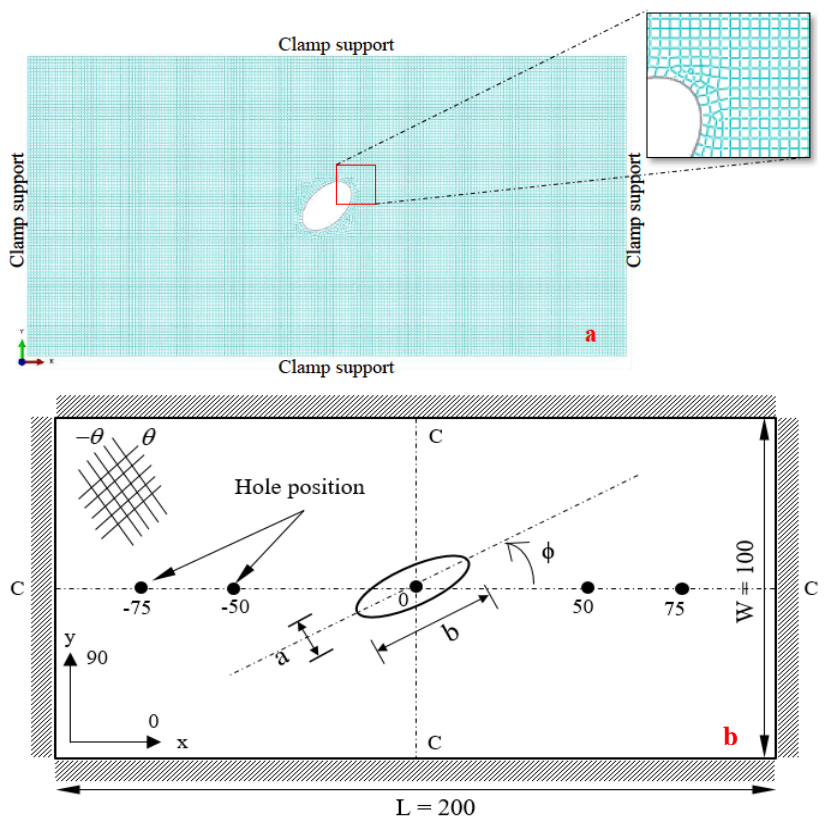

Figure 3: (a) Meshing of the plate with elliptical hole and (b) geometric modeling

\subsection{Validation of numerical modeling}

In this validation, the dimension of symmetric laminate composite plates was $76 \mathrm{~mm} \times 76 \mathrm{~mm} \times 1.04 \mathrm{~mm}$ (plate aspect ratio 1) and $152 \mathrm{~mm} \times 76 \mathrm{~mm} \times 1.04 \mathrm{~mm}$ (plate aspect ratio 2) with 8 layers. Each ply thickness was taken as $0.13 \mathrm{~mm}$. The plates with each aspect ratio were orientated of $[0 / 0 / 30 /-30]_{s},[0 / 45 /-45 / 90]_{s}$ and $[45 /-45 /-45 / 45]_{s}$. The present finite element analysis was used the same material properties to those used by Crawley [26]. The results of this present study were validated for plates having aspect ratios 1 and 2 as illustrated in Table 3. It can be seen that the present finite element and observed results was initiated to be reasonable, but it has some differences. This inconsistency was due to reduction values of transverse shear stiffness in the finite element model. However, a reduction of $20 \%$ in transverse shear modulus lowered frequencies less than $1 \%$. Furthermore, the in-plane stiffness used in the finite element analysis is too high, and that the dynamic flexural modulus is lower than the static extensional modulus as explained by Pingulkar and Suresha [27]. 
Table 3: Validation of natural frequencies of $76 \mathrm{~mm} \times 76 \mathrm{~mm}$ and $152 \mathrm{~mm} \times 76 \mathrm{~mm}$ graphite epoxy cantilever plates

\begin{tabular}{lcccccccc}
\hline \multirow{2}{*}{ Laminate } & \multirow{2}{*}{ Mode } & \multicolumn{3}{c}{$76 \mathrm{~mm} \times 76 \mathrm{~mm}$ plates } & & \multicolumn{2}{c}{$152 \mathrm{~mm} \times 76 \mathrm{~mm}$ plates } \\
\cline { 3 - 5 } \cline { 8 - 9 } & & Ref [26] & Presents & \% Diff & & Ref [26] & Presents & \% Diff \\
\hline \multirow{2}{*}[0/0/30/-30]{$_{s}$} & 1 & 234.20 & 261.26 & 10.36 & & 58.30 & 65.24 & 10.63 \\
& 2 & 362.00 & 361.88 & -0.03 & & 148.00 & 136.89 & -8.12 \\
& 3 & 728.30 & 755.97 & 3.66 & & 362.70 & 407.13 & 10.91 \\
{$[0 / 45 /-45 / 90]_{s}$} & 1 & 196.40 & 223.57 & 12.15 & & 48.60 & 55.45 & 12.35 \\
& 2 & 418.00 & 419.24 & 0.30 & & 169.00 & 174.42 & 3.11 \\
& 3 & 960.00 & 1004.50 & 4.43 & & 303.00 & 344.36 & 12.01 \\
{$[45 /-45 /-45 / 45]_{s}$} & 1 & 131.20 & 137.66 & 4.69 & & 31.30 & 31.82 & 1.64 \\
& 2 & 472.00 & 493.53 & 4.36 & & 185.80 & 190.52 & 2.48 \\
& 3 & 790.50 & 789.55 & -0.12 & & 214.00 & 226.29 & 5.43 \\
\hline
\end{tabular}

\section{Sensitive analysis of the natural frequency of BFRP laminate composite plate}

\subsection{Effect of stacking sequence on the natural frequency}

To illustrate the effect of the fiber orientation angle on the natural frequency of symmetrical laminate composite plates with regards to the elliptical hole as shown in Figure 4 , the hole geometric ratio $(\mathrm{a} / \mathrm{b}=0.5)$ with clamp supports for all edges was considered. It can be seen that the largest values of natural frequency were obtained when the major axis of elliptical hole equals to $\phi=90^{\circ}$ regardless ply angle. And the composite plates with elliptical hole $\phi=0^{\circ}$ offer the smallest resistance to free vibration. Furthermore, it can be noted that the composite plate with fiber orientation angle $\left(\theta=45^{\circ}\right)$ provided the smallest natural frequency, while the greatest values of natural frequency were achieved for the plate with ply angle $\theta=0^{\circ}$

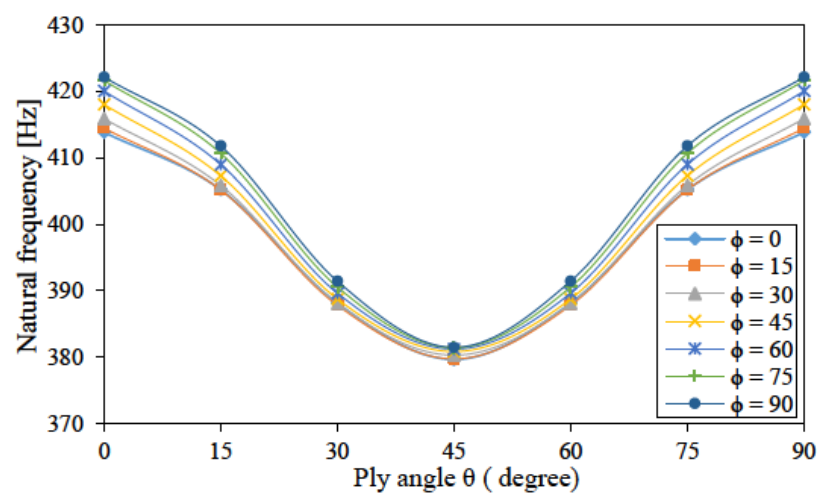

Figure 4: Natural frequency fiber orientation angle versus elliptical hole inclination $(\mathrm{a} / \mathrm{b}=0.5 ; \mathrm{BC}=\mathrm{CCCC})$ and $90^{\circ}$. Thus, it can be noted that, to avoid reduction of the resistance to free vibration, the laminate composite plate should not be oriented at $\theta=45^{\circ}$.

\subsection{Effect of hole geometric ratio on the natural frequency}

The effect of the hole geometric ratio $(\mathrm{a} / \mathrm{b})$ was also studied for different stacking sequences of laminate composite plate with elliptical hole inclination $\phi=45^{\circ}$. The major axis of elliptical hole was maintained constant ( $b=$ $20 \mathrm{~mm}$ ) and minor axis (a) varied for each case. Clamp support for all edges were performed. As illustrated in Figure 5 , it can be seen that the composite plate with stacking sequence $[90 / 0 / 90 / 0]_{s}$ provided the greatest natural frequency, while the lowest natural frequency values were obtained with stacking sequence $[45 /-30 / 60 /-45]_{s}$. It can also be observed that the natural frequency increases linearly with the increasing of hole aspect ratio for all stacking sequences. Although cut-out can reduce stiffness of composite plate, the reduced mass of the plate was more prominent which resulted in the increment of natural frequency. Thus, it can be concluded that the bigger the composite plate cut-out, the greater the resistance of composite plate to the free vibration.

The influence of the elliptical hole inclination on the variation of natural frequency was illustrated in Figure 6 for several geometric ratios $(a / b)$. The laminate composite plate studied in this case was symmetrical of type $[90 / 0 / 90 / 0]_{s}$. Figure 6 shows an exponential increase of natural frequency for the increment of elliptical hole inclination of the laminate composite plate for the geometric ratios $(\mathrm{a} / \mathrm{b})$ smaller than 1.0. For cases where $\phi<60^{\circ}$, it can be noted that the maximum values of natural frequency were obtained for the composite plate with geo- 


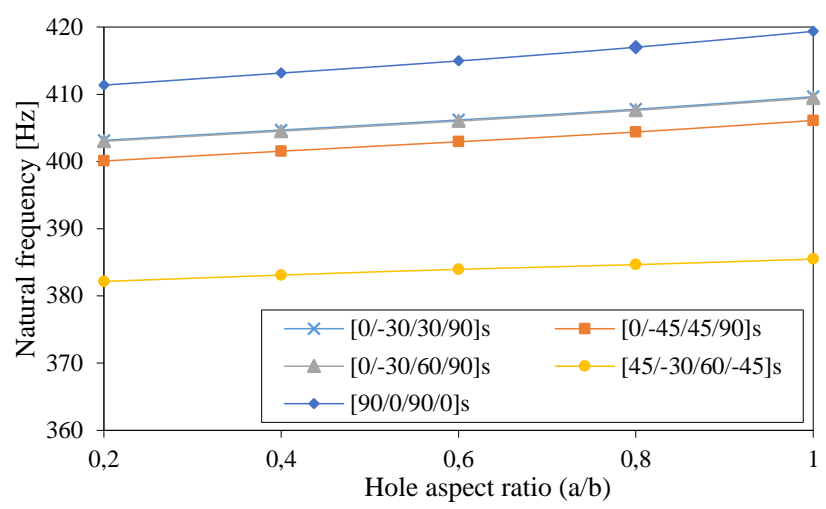

Figure 5: Effect of a/b ratio on the variation of natural frequency $(\phi$ $=45 ; \mathrm{BC}=\mathrm{CCCC})$

metric ratio $(a / b=1.0)$. While, the composite plate with geometric ratio $(a / b=0.2)$ yields the minimum values of natural frequencies. In contrast, for cases where $\phi \geq 60^{\circ}$, it can be seen that the composite plate with the greatest resistance to free vibration were obtained, when $\mathrm{a} / \mathrm{b}=0.2$. While the composite plate with geometric ratio $(a / b=1)$ provided the smallest values of natural frequencies. Additionally, according to Figure 6, it can be concluded that the natural frequency was less affected by the hole inclination when the geometric ratio getting bigger.

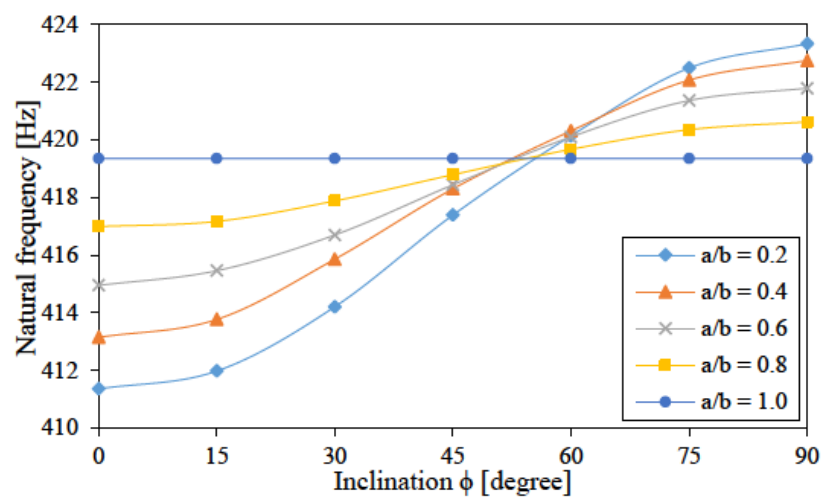

Figure 6: Effect of elliptical hole inclination on the variation of natural frequency $(B C=C C C C ; \theta=[90 / 0 / 90 / 0] s)$

\subsection{Effect of the hole position}

Figure 7 shows the natural frequency curve when the position of the center of the elliptical hole changes with regards to the free vibration. The effect of fiber orientation angle with the geometric ratio $(\mathrm{a} / \mathrm{b}=0.5)$ was highlighted. The presence of elliptical hole inclination $\phi \leq 45^{\circ}$ was considered. Clamp support on one edge and three free edge
(CFFF) was studied. Figure 7 shows that the maximum values of natural frequency were obtained when the composite plate had a stacking sequence $[90 / 0 / 90 / 0]_{s}$. While the plate with ply angle $[45 /-30 / 60 /-45]_{s}$ provided the minimum values of natural frequencies. It can also be seen that the natural frequency increases linearly when the center of elliptical hole position farther away from the support. This was due to the decrement of the composite plate stiffness when transferring vibration to the support when cut-out was closer to the support. Therefore, it can be concluded that, to avoid obtaining lower resistance to free vibration, the laminate composite plate shouldn't be cut-out near the support.

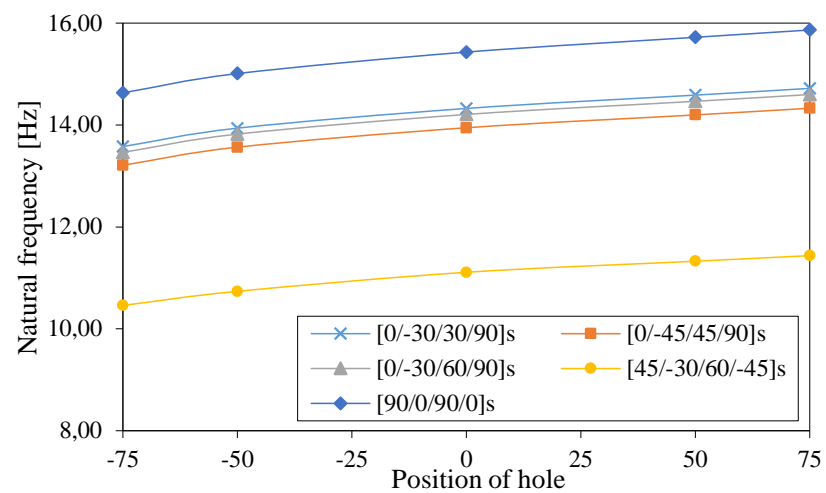

Figure 7: Effect of hole position on the natural frequency $(a / b=0.5$; $\phi=45 ; \mathrm{BC}=$ (FFF)

\section{Correlation of natural frequency with buckling load}

\subsection{Mode shapes under free vibration and buckling load of laminate composite plates}

Figure 8 shows the mode shapes of free vibration and buckling load (bi-axial load). The symmetric laminate composite plate with stacking sequence $[0 / 0 / 0 / 0]_{s}$ was studied. Also, the geometric ratio $(\mathrm{a} / \mathrm{b}=0.6)$ and clamp support for all edges was considered. Five mode shapes of free vibration and buckling load were investigated. Based on Figure 8 , it is interesting to observed that mode shapes of composite plate under free vibration were similar to those of buckling load, for mode shapes I, II and III. However, those mode shapes were different for the mode shapes IV and V. 


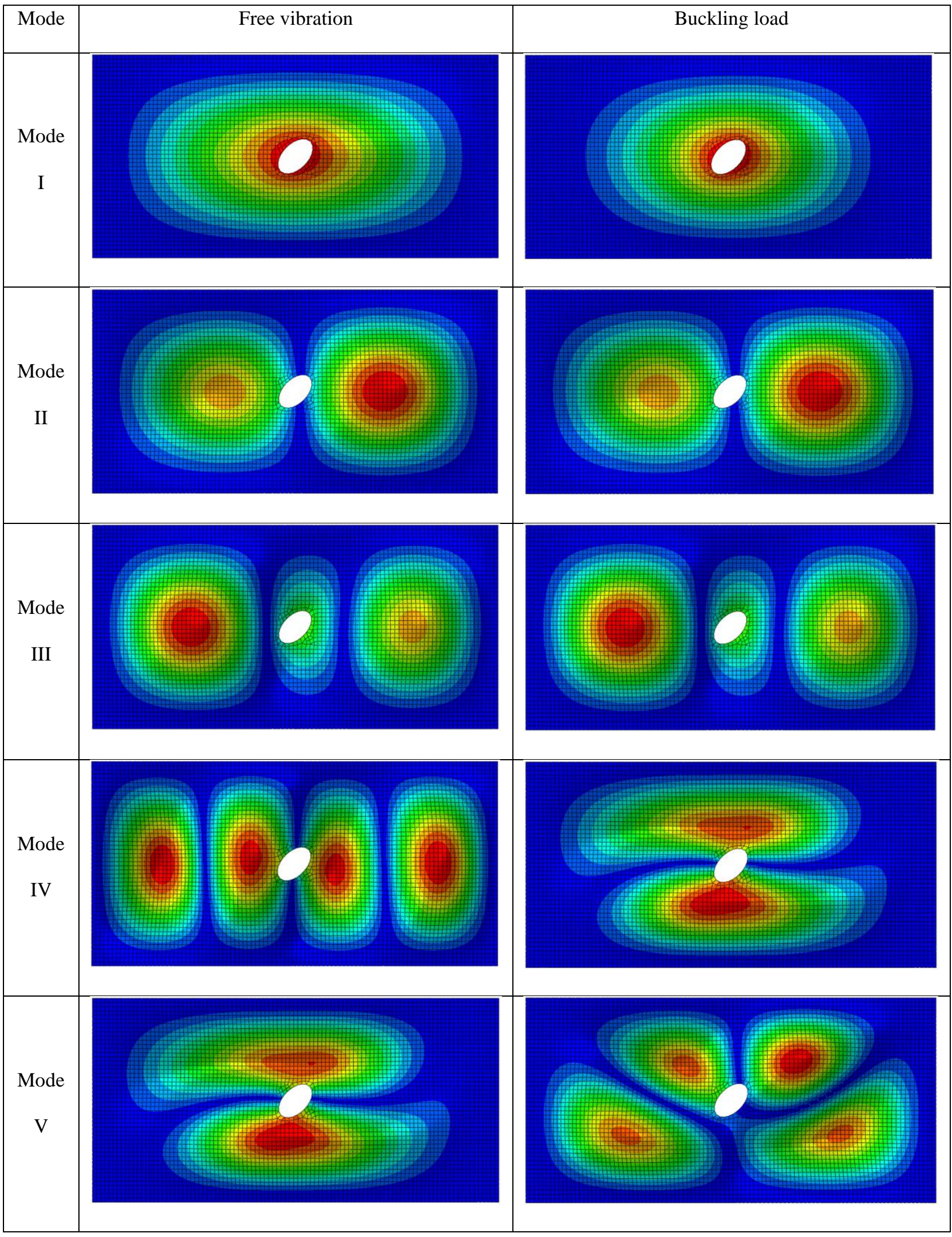

Figure 8: Mode shapes of free vibration and buckling load 


\subsection{Effect of elliptical hole inclination}

The correlation of free vibration and buckling load of the composite plate with clamp support on all edges were studied. The effects of elliptical hole inclination and fiber orientation angle were considered. The correlation curves were determined based on the plotted of data points of various fiber angles. With the presence of hole cut-out, four cases $(\mathrm{a} / \mathrm{b}=0.2,0.4,0.6$ and 0.8$)$ were investigated. As shown in Figure 9 and 10 , the correlation coefficient $(r)$ of natural frequency and buckling load had a negative value. This negative correlation coefficient showed the inverse proportion between natural frequency and buckling load, i.e. natural frequency decrease as the buckling load increased. Moreover, it was illustrated that the composite plate with elliptical hole inclination $\phi=0^{\circ}$ had the strongest correlation between natural frequency and buckling load, while the lowest was obtained from the plate with elliptical hole inclination $\phi=90^{\circ}$ regardless geometric ratio. Thus, it can be concluded that elliptical hole inclination as well as fiber orientation angle induced the inverse proportion between natural frequency and buckling load.
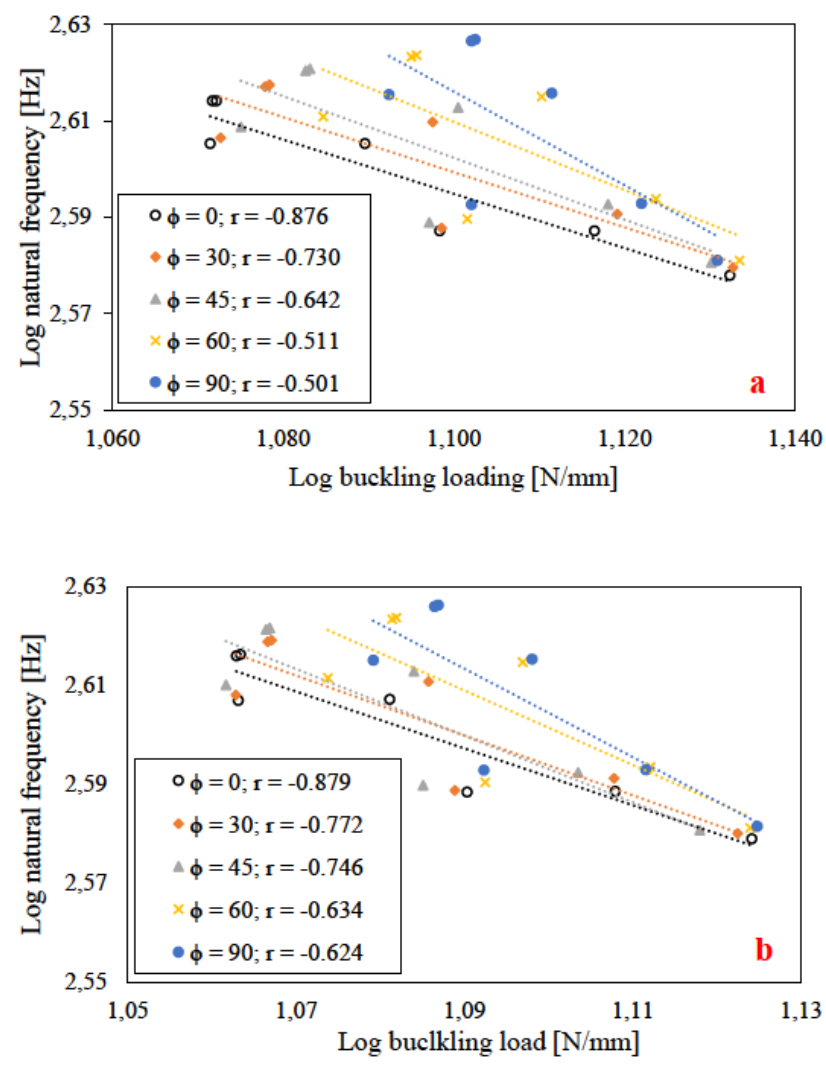

Figure 9: Correlation of natural frequency and buckling load: (a) $a / b$ $=0.2$ and $(\mathrm{b}) \mathrm{a} / \mathrm{b}=0.4$
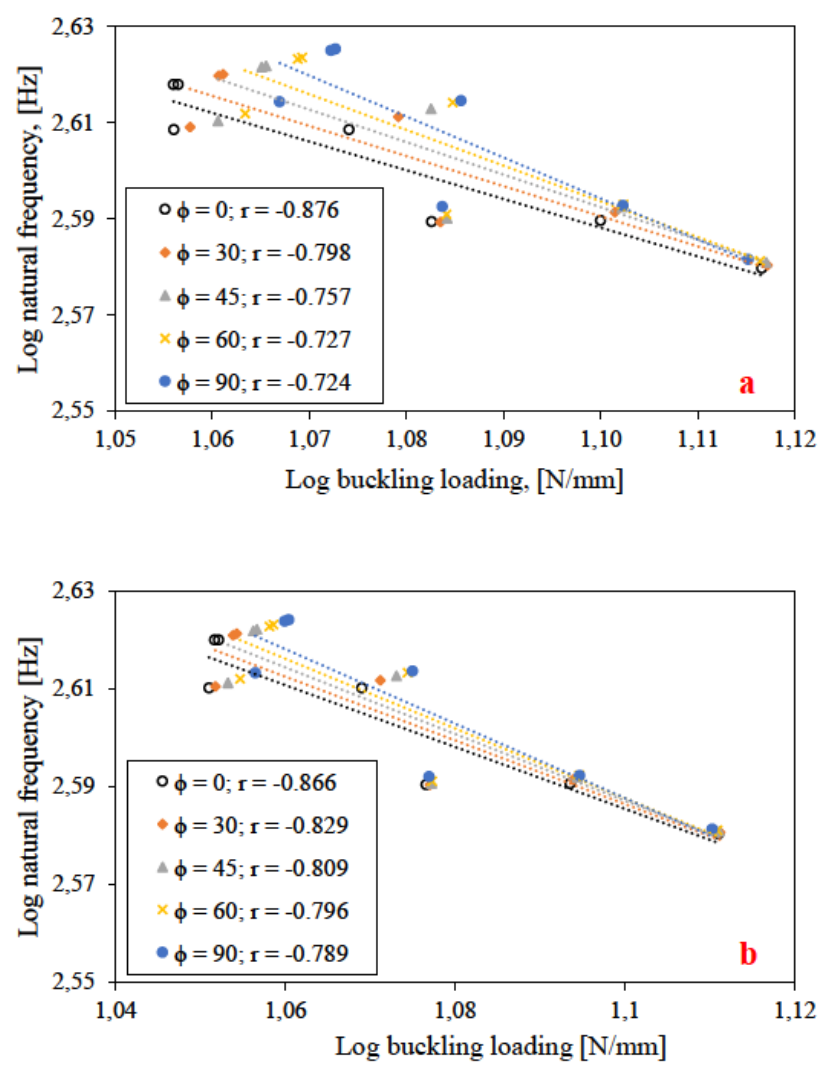

Figure 10: Correlation of natural frequency with buckling load: (a) $\mathrm{a} / \mathrm{b}=0.6$ and $(\mathrm{b})=0.8$

According to Figure 9(a) and 9(b), it can also be seen that each correlation curve was widely separated from each other. This was due to the significant effect of elliptical hole inclination on the laminate composite plate that caused a large gap of buckling load. In contrast, the small gap between each curve was obtained when the composite plates had the geometric ratio greater than 0.6 as illustrated in Figure 10(a) and 10(b). Thus, it can be noted that when the geometric ratio $a / b \geq 0.6$, the curves were close to each other. From these curves, it was also observed that the plate with elliptical hole inclination parallel to the width of the plate provided the maximum values for both natural frequency and buckling load, while the minimum values were obtained for the plates with hole inclination perpendicular to width of the plate.

\section{Conclusions}

The application and design parameters have great effect on the failure mode of a structure. In this study, the free vibration analysis of symmetric rectangular laminate composite plate with the elliptical hole was considered. The ef- 
fects of fiber orientation angle, elliptical hole inclination, geometric ratio and hole position were highlighted. The numerical modeling of free vibration analysis was based on the mechanical properties of BFRP obtained from the experiment. The mode shapes and natural frequencies of basalt laminates composite plates were obtained from the numerical analysis with the commercial program software (ABAQUS). Then, the determination of correlation of natural frequencies with buckling load was carried out. The following conclusions can be drawn:

- In case of clamp support for all edges, to obtain the highest vibration resistance, the major axis of the elliptical hole should cut-out parallel to the width of the plate regardless of the fiber orientation angle.

- In case CFFF, to avoid the decrement of natural frequency of the laminate composite plates, the plate should not be cut-out near the boundary.

- The laminate composite plate with smaller elliptical cut-out provide lower natural frequency, while the greater natural frequency was obtained from the plate with bigger cut-out. This was owing to the reduction of mass of the plate was more predominant than the reduction of their stiffness. The elliptical hole inclination had a smaller effect on the natural frequency of laminate composite plate, when the geometric ratios was bigger.

- It can be noted that mode shapes of free vibration as well as buckling load were almost the same for modes I, II and III. However, those of mode shapes IV and $\mathrm{V}$ were different.

- The composite plate with elliptical hole inclination parallel to the width of the plate provided the strongest correlation between natural frequency and buckling, while the lowest correlation was obtained for the plate with elliptical hole inclination perpendicular to the width of plate regardless geometric ratio.

- It can be concluded that elliptical hole inclination and the fiber orientation angle induced the inverse proportion between natural frequency and buckling load.

- For plates with geometric ratio $\mathrm{a} / \mathrm{b}=0.2$ and 0.4 , each correlation curve was widely separated from each other. This was owing to the significant effect of elliptical hole inclination on the laminate composite plate that caused a large gap of buckling load. In contrast, the small gap between each curve was obtained when the composite plate with geometric ratio greater than 0.6
Acknowledgement: This present work was supported by the National Research Foundation [NRF] grant funded by the Korea government [MEST] [No.2017R1A2B3008623].

\section{References}

[1] Pıhtılı H, Tosun N. Effect of load and speed on the wear behaviour of woven glass fabrics and aramid fibre-reinforced composites. Wear. 2002 Jul;252(11-12):979-84.

[2] Aniskevich K, Aniskevich A, Arnautov A, Jansons J. Mechanical properties of pultruded glass fiber-reinforced plastic after moistening. Compos Struct. 2012 Sep;94(9):2914-9.

[3] Chhorn B, Jung W. Evaluation of Buckling Resistance of Basalt Fiber Reinforced Polymer Plate. Civ Eng (Shiraz). 2020 Jan;1-2: https://doi.org/10.1007/s40996-019-00344-1.

[4] Chhorn, B., \& Jung, W. Parametric Study on Buckling Resistance of the Thin BFRP (Basalt Fiber Reinforced Polymer) Plate Subjected to Combined Loading. Journal of the Korean Society for Advanced Composite Structures, 10(1), 1-9. https://doi.org/10.11004/kosacs.2019.10.1.001.

[5] Chandrashekhara K, Krishnamurthy K, Roy S. Free vibration of composite beams including rotary inertia and shear deformation. Compos Struct. 1990 Jan;14(4):269-79.

[6] Turvey GJ, Mulcahy N, Widden MB. Experimental and computed natural frequencies of square pultruded GRP plates: effects of anisotropy, hole size ratio and edge support conditions. Compos Struct. 2000 Dec;50(4):391-403.

[7] Liew KM, Kitipornchai S, Leung AY, Lim CW. Analysis of the free vibration of rectangular plates with central cut-outs using the discrete Ritz method. international journal of mechanical sciences. 2003 May 1;45(5):941-59. https://doi.org/10.1016/S00207403(03)00109-7.

[8] Aydogdu M. Free vibration analysis of angle-ply laminated beams with general boundary conditions. J Reinf Plast Compos. 2006 Oct;25(15):1571-83.

[9] Erkliğ A, Bulut M, Yeter E. Effects of cutouts on natural frequency of laminated composite plates. Science and Engineering of Composite Materials. 2013 May 1;20(2):179-85. https://doi.org/10.1515/secm-2012-0120.

[10] Jhung MJ, Choi YH, Ryu YH. Free vibration analysis of circular plate with eccentric hole submerged in fluid. Nucl Eng Technol. 2009;41(3):355-64.

[11] Ovesy HR, Fazilati J. Buckling and free vibration finite strip analysis of composite plates with cutout based on two different modeling approaches. Compos Struct. 2012 Feb;94(3):1250-8.

[12] Sivakumar K, lyengar NG, Deb K. Optimum design of laminated composite plates with cutouts using a genetic algorithm. Compos Struct. 1998 Jul;42(3):265-79.

[13] Kumar A, Shrivastava RP. Free vibration of square laminates with delamination around a central cutout using HSDT. Compos Struct. 2005 Sep;70(3):317-33.

[14] Tornabene F, Fantuzzi N, Bacciocchi M. Higher-order structural theories for the static analysis of doubly-curved laminated composite panels reinforced by curvilinear fibers. Thin-walled Struct. 2016 May;102:222-45.

[15] Sahu SK, Datta PK. Dynamic stability of curved panels with cutouts. J Sound Vibrat. 2002 Apr;251(4):683-96. 
[16] Reddy AK, Palaninathan R. Free vibration of skew laminates. Comput Struc. 1999 Feb;70(4):415-23.

[17] Srinivasa CV, Suresh YJ, Kumar WP. Free flexural vibration studies on laminated composite skew plates. Int J Eng Sci Technol. 2012;4(4):13-24.

[18] Srinivasa CV, Sures YJ, Kumar WP. Free flexural vibration studies on skew plates [IJALS]. International Journal of Aerospace and Lightweight Structures. 2012 Jul;2(3):405-20.

[19] Srinivasa CV, Suresh YJ, Kumar WP. Experimental and finite element studies on free vibration of skew plates [IJASE]. International Journal of Advanced Structural Engineering. 2014 Mar;6(1):48.

[20] Srinivasa CV, Suresh Y], Kumar WP. Finite element studies on free vibration of laminated composite cylindrical skew panels. International Journal of Applied Mechanics and Engineering. 2014 Feb;19(1):165-80.

[21] Kumar SK, Harursampath D, Carrera E, Cinefra M, Valvano S. Modal analysis of delaminated plates and shells using Carrera Unified Formulation-MITC9 shell element. Mech Adv Mater Structures. 2018 Jun;25(8):681-97.
[22] Alaimo A, Orlando C, Valvano S. An alternative approach for modal analysis of stiffened thin-walled structures with advanced plate elements. Eur J Mech A, Solids. 2019 Sep;77:103820.

[23] ASTM D2344/D2344 M-03 (2003) Standard test method for shortbeam strength of polymer matrix composite materials and their laminates. American Society for Testing and Materials, West Consohocken, PA.

[24] ASTM D 3039/D 3039M - 00 (2000) Standard test method for tensile properties of polymer matrix composite materials. American Society for Testing and Materials, West Consohocken, PA.

[25] ASTM D 4255/D 4255M - 01 (2001) Standard test method for in-plane shear properties of polymer matrix composite materials by the rail shear method. American Society for Testing and Materials, West Consohocken, PA.

[26] Crawley EF. The natural modes of graphite/epoxy cantilever plates and shells. J Compos Mater. 1979 Jul;13(3):195-205.

[27] Pingulkar P, Suresha B. Free vibration analysis of laminated composite plates using finite element method. Polymers and Polymer Composites. 2016 Sep;24(7):529-38. https://doi.org/10.1177/096739111602400712. 